\title{
Salivary Levels of Uric Acid, Lactate Dehydroge- nase, and Amylase in Smokers Versus Non-Smokers
}

\author{
Simin Lesan ${ }^{1}$, Mandana Khatibi ${ }^{1 D}$, Sina Firoozan ${ }^{3}$ \\ ${ }^{1}$ Oral Medicine Dept, Faculty of Dentistry,Tehran Medical Sciences, Islamic Azad University, Tehran, Iran. \\ ${ }^{2}$ Oral Medicine Dept, Faculty of Dentistry, Tehran Medical Sciences, Islamic Azad University, Tehran, Iran. \\ ${ }^{3}$ Private Practice, Tehran, Iran
}

\begin{tabular}{l} 
ARTICLE INFO \\
\hline Article History \\
Received:May 2021 \\
Accepted: Apr 2021 \\
ePublished: June 2021 \\
Corresponding author: \\
M Khatibi, Oral Medicine \\
Dept, Faculty of Dentist- \\
ry,Tehran Medical Sciences, \\
Islamic Azad University, \\
Tehran, Iran. \\
Email: mandanakhatibi@ \\
yahoo.com
\end{tabular}

\begin{abstract}
Background and Aim: Smoking is a hazardous habit with numerous adverse effects on oral health. It plays an important role in development of cancerous and precancerous lesions and periodontal disease. Saliva has an antioxidant system and several enzymes. This study aimed to assess the salivary levels of uric acid (UA), lactate dehydrogenase (LDH), and amylase in smokers versus non-smokers.

Materials and Methods: This descriptive, cross-sectional study was conducted on 60 individuals (30 smokers and 30 non-smokers) at the Dental School of Islamic Azad University. The participants were requested to refrain from smoking, eating and drinking prior to saliva sampling. A minimum of $1 \mathrm{cc}$ of unstimulated saliva was collected from each participant by the spitting method. The level of salivary LDH was measured by the DGKC method, the level of UA was measured by the uricase assay, and the level of amylase was quantified by the kinetic photometric method. Data were analyzed by t-test, Chi-square test, Fisher's exact test, and Mann-Whitney test $(\mathrm{P}<0.05)$.

Results: The salivary level of UA was $1.35 \pm 1.2 \mathrm{mg} / \mathrm{dL}$ and $1.08 \pm 1.05 \mathrm{mg} / \mathrm{dL}$ in smokers and nonsmokers, respectively with no significant difference $(\mathrm{P}=0.08)$. The salivary levels of amylase and LDH were $44509 \pm 38062 \mathrm{U} / \mathrm{L}$ and $420 \pm 244 \mathrm{IU} / \mathrm{L}$ in smokers and $47299 \pm 29659 \mathrm{U} / \mathrm{L}$ and $538 \pm 350 \mathrm{IU} / \mathrm{L}$ in non-smokers, respectively, with no significant difference $(\mathrm{P}>0.05)$.

Conclusion: Despite the slightly higher level of salivary UA in smokers, the difference between smokers and non-smokers was not significant in any of the tested parameters.
\end{abstract}

J Res Dent Maxillofac Sci 2021;6(3):18-22.

Keywords: Amylase; Cigarette Smoking; Lactate Dehydrogenase; Uric Acid

\section{Introduction}

Smoking is a hazardous habit with numerous adverse effects on oral health. It plays an important role in development of cancerous and precancerous lesions and periodontal disease. Cigarette smoke includes toxic compounds such as aldehydes, carbon monoxide, hydrogen cyanide, benzopyrene, and oxygen radicals. These components can cause systemic conditions such as cardiovascular and pulmonary diseases. Oxygen free radicals may cause cytotoxic changes in the internal or external cellular components such as lipids, proteins, and DNA, and impair the cell function. ${ }^{(1,2)}$
The prevalence of squamous cell carcinoma in smokers is 4-7 times the rate in non-smokers. ${ }^{(3)}$ According to the World Health Organization, approximately one-third of the world's population over 15 years of age have tobacco consumption. ${ }^{(4)}$

Saliva is the first body fluid exposed to cigarette smoke, and is also the firstline defense mechanism against oxidative stress. ${ }^{(5)}$ The salivary antioxidant system plays an important role in its anti-carcinogenic property, and includes several enzymes and molecules such as uric acid (UA) and peroxidase system. 
UA, albumin, and ascorbic acid are the main antioxidants in the saliva. ${ }^{(6)}$ Exposure of saliva to cigarette smoke has shown some changes in the salivary concentration of lactate dehydrogenase $(\mathrm{LDH})$, amylase, and UA both in vivo and in vitro; these factors are important antioxidants of the saliva. ${ }^{(7)} \mathrm{UA}$ is one of the most important non-enzymatic antioxidants. ${ }^{(2,5,6,8)}$ Also, it has been demonstrated that salivary enzymes such as amylase, acid phosphatase, and LDH are affected by the cigarette smoke. ${ }^{(2,4,9,10)}$ Kanehira et al. ${ }^{(1)}$ reported that the salivary levels of thiocyanate and superoxide dismutase in smokers were higher than the corresponding values in non-smokers.

Baharvand et al. ${ }^{(2)}$ reported significantly higher activity of superoxide dismutase in smokers than non-smokers. Buduneli et al. ${ }^{(6)}$ demonstrated a reduction in total salivary glutathione of smoker patients with gingivitis. Zappacosta et al. ${ }^{(8)}$ found no significant difference in the salivary level of UA and entrapped radicals in smokers and nonsmokers. Reznick et al. ${ }^{(11)}$ reported a significant reduction in the activity of oral peroxidase in smokers and non-smokers. Decreased activity of oral peroxidase was associated with increased carbonylation of salivary proteins, which served as an indicator of oxidative damage of proteins. The oral epithelium of heavy smokers cannot be protected by oral peroxidase against the adverse effects of thiocyanate ions and hydroxyl radicals generated by hydrogen peroxide. This may lead to initiation or progression of tumorigenesis induced by cigarette smoke. ${ }^{(11)}$ Evidence shows the suppression of salivary antioxidant protective system in smokers against the accumulated stresses in the oral cavity. ${ }^{(12)}$ Some studies found no significant difference in salivary level of UA and LDH between smokers and non-smokers. ${ }^{(8,11,13)}$

Considering the existing controversy in the results of studies, ${ }^{(8,11,13)}$ this study aimed to assess and compare the salivary levels of UA, LDH and amylase in smokers and non-smokers presenting to the Oral Medicine Department of Islamic Azad University.

\section{Materials and Methods}

This descriptive analytical study was conducted on 30 smoker and 30 non-smoker individuals that were selected among those presenting to the
Oral Medicine Department of School of dentistry, Islamic Azad University. ${ }^{(2)}$ The case group included smokers who reported smoking 10 cigarettes daily for the past 5 years, and were systemically healthy. ${ }^{(6)}$ The control group included non-smokers who matched the smoker group in terms of age, gender, plaque index, bleeding on probing, clinical attachment loss, and medication intake, and were also systemically healthy. Sampling was targeted, and data were collected by clinical examination, interviewing the patients, reviewing the medical records of patients, and asking them to fill out an information form. The Turesky, Gilmore, Glickman modification of the Quigley-Hein plaque index was used to calculate the plaque index of patients as follows:

Zero: No plaque

1: Separate areas of plaque at the cervical margin 2: A thin continuous band of plaque $>1 \mathrm{~mm}$ at the cervical margin

3: A band of plaque with $>1 \mathrm{~mm}$ width covering $<1 / 3$ of the crown

4: Plaque covering $1 / 3$ to less than $2 / 3$ of the crown

5: Plaque covering $>2 / 3$ of the crown

Also, the clinical attachment loss was evaluated to determine the periodontal status as follows:

Mild: Less than $2 \mathrm{~mm}$

Moderate: 2-4 mm

Severe: $>4 \mathrm{~mm}^{(6)}$

Patients with grade 3 or higher clinical attachment loss were excluded. ${ }^{(6)}$ The patients were informed about the study, and requested to refrain from smoking for at least $1 \mathrm{~h}$ prior to saliva collection. They were also requested to refrain from eating and drinking for $2 \mathrm{~h}$ prior to saliva collection. Saliva was collected between 9-10 a.m. after rinsing the mouth with water, with patient at resting position. A minimum of $1 \mathrm{cc}$ of unstimulated saliva was collected by the spitting method ${ }^{(14)}$ and transferred to a laboratory within $24 \mathrm{~h}$. The salivary level of LDH was measured by the DGKC method, which is based on the conversion of pyruvate to lactase. ${ }^{(15)}$ This is an oxidation-reduction reaction. Two solutions $(1 \mathrm{cc})$ are mixed with $10 \mu \mathrm{L}$ of the saliva, and the optical density of the mixture is read at 340 $\mathrm{nm}$ wavelength at $37^{\circ} \mathrm{C}$ (normal value should be $430 \mathrm{IU} / \mathrm{L}){ }^{(15)}$ The salivary level of UA was measured by the uricase assay using Accurex UA 
kit (India). Similarly, two solutions were mixed with the saliva, and the optical density was read at $500-530 \mathrm{~nm}$ (normal range is $3.6-8.2 \mathrm{mg} / \mathrm{dL}$ in males and $2.3-6.1 \mathrm{mg} / \mathrm{dL}$ in females). ${ }^{(16)}$ The salivary level of amylase was measured by the kinetic photometric enzymatic technique.

For this purpose, two solutions $(1 \mathrm{cc})$ were mixed with $10 \mu \mathrm{L}$ of the saliva and the optical density of he mixture was read at $405 \mathrm{~nm}$ wavelength (normal range is $>491 \mathrm{U} / \mathrm{L}$ in males and $>447 \mathrm{U} / \mathrm{L}$ in females). ${ }^{(17)}$ Data were analyzed using t-test, Chi-square test, Fisher's exact test, and Mann-Whitney test at $\mathrm{P}<0.05$ level of significance.

\section{Results}

This study evaluated 30 smokers and 30 nonsmokers. Table 1 presents the characteristics of the two groups. As shown, the two groups were similar regarding socioeconomic level (presenting to one center), age, sex, and periodontal status (gingival recession, bleeding on probing), medication intake, and plaque index $(\mathrm{P}>0.05)$.

Table 2 shows the salivary levels of UA, LDH and amylase. The results showed that the level of UA in the case group was $0.3 \mathrm{mg} / \mathrm{dL}$ or $28.8 \%$ higher than that in the control group $(\mathrm{P}=0.08)$. The LDH and amylase levels were also slightly higher in the case group but not significantly $(\mathrm{P}>0.05)$.

Table 1. Characteristics of the two groups

\begin{tabular}{|c|c|c|c|c|c|c|c|c|}
\hline \multirow{2}{*}{$\begin{array}{c}\text { Properties } \\
\text { Group }\end{array}$} & \multirow[t]{2}{*}{ Age } & \multicolumn{2}{|c|}{ Gender } & \multirow{2}{*}{$\begin{array}{l}\text { Clinical } \\
\text { attachment } \\
\text { loss }\end{array}$} & \multicolumn{2}{|c|}{$\begin{array}{l}\text { Bleeding on } \\
\text { probing }\end{array}$} & \multirow{2}{*}{$\begin{array}{l}\text { Medication } \\
\text { intake }\end{array}$} & \multirow{2}{*}{$\begin{array}{l}\text { Plaque } \\
\text { index }\end{array}$} \\
\hline & & Male & Female & & + & $\begin{array}{ll}- \\
-\end{array}$ & & \\
\hline $\begin{array}{l}\text { Control } \\
\text { group } \\
(\mathrm{N}=30)\end{array}$ & $\begin{array}{l}32.8 \pm \\
8.22\end{array}$ & $\begin{array}{c}28 \\
(93.3)\end{array}$ & $\begin{array}{c}2 \\
(6.7)\end{array}$ & $\begin{array}{l}1.23 \pm \\
0.43\end{array}$ & $\begin{array}{c}21 \\
(70)\end{array}$ & $\begin{array}{c}9 \\
(30)\end{array}$ & 0 & $\begin{array}{c}91.83 \\
\pm \\
12.06\end{array}$ \\
\hline $\begin{array}{l}\text { Case } \\
\text { group } \\
(\mathrm{N}=30)\end{array}$ & $\begin{array}{l}32.93 \\
\pm 8.55\end{array}$ & $\begin{array}{c}28 \\
(93.3)\end{array}$ & $\begin{array}{c}2 \\
(6.7)\end{array}$ & $\begin{array}{l}1.23 \pm \\
0.43\end{array}$ & $\begin{array}{l}21 \\
(70)\end{array}$ & $\begin{array}{c}9 \\
(30)\end{array}$ & 0 & $\begin{array}{l}94.17 \\
\pm 8.52\end{array}$ \\
\hline$P$ value & 0.9523 & \multicolumn{2}{|c|}{$<0.99$} & $\mathrm{P}<0.99$ & & & - & $\begin{array}{c}\mathrm{P}= \\
0.767\end{array}$ \\
\hline
\end{tabular}

\section{Discussion}

In this study, the salivary level of UA in smokers was slightly, but not significantly, higher than that of non-smokers, which was in agreementwiththeresults ofPullisheryetal. ${ }^{(18)}$ Zappacostaetal ${ }^{(8)}$ andAbdolsamadietal. ${ }^{(13)}$ reported no significant difference in level of UA in smokers and non-smokers. Fatima et al. ${ }^{(14)}$ showed that the level of UA in smokers with periodontitis was slightly, but not significantly, lower than that in smokers without periodontitis. However, Greabu et al. ${ }^{(19)}$ reported that cigarette smoke significantly decreased the level of UA. The antioxidant system of the saliva plays a fundamental role in anti-carcinogenic capacity of the saliva, and is mainly based on the UA. UA is a major salivary anti-oxidant. ${ }^{(8)}$ Variations in the results are probably due to the variations in methodology. This study had an in vivo design, and saliva was collected at least $1 \mathrm{~h}$ after smoking. This time is sufficient for the release of saliva along with anti-oxidant molecules into the oral cavity and subsequent increase in the level of salivary UA. However, Greabu et al, ${ }^{(16)}$ in their in vitro study and some others ${ }^{(4,20,21)}$ reported significant reduction of UA in smokers. This difference may be due to the fact that saliva was evaluated in this study while the abovementioned studies evaluated the serum level of UA. It has been reported that reduction in serum level of UA may be related to decreased protection against the oxidative stress. ${ }^{(22)}$

Table 2. Salivary levels of UA, LDH and amylase in the two groups of smokers and non-smokers

\begin{tabular}{llll}
\hline $\begin{array}{l}\text { Salivary } \\
\text { antioxidant }\end{array}$ & $\begin{array}{c}\mathrm{U} . \mathrm{A} \\
(\mathrm{mg} / \mathrm{dl})\end{array}$ & $\begin{array}{c}\mathrm{LDH} \\
(\mathrm{U} / \mathrm{L})\end{array}$ & $\begin{array}{c}\text { Amylase } \\
(\mathrm{U} / \mathrm{L})\end{array}$ \\
\hline $\begin{array}{l}\text { Control group } \\
(\mathrm{N}=30)\end{array}$ & $1.05 \pm 1.08$ & $538 \pm 350$ & $47299 \pm 29659$ \\
$\begin{array}{l}\text { Case group } \\
(\mathrm{N}=30)\end{array}$ & $1.35 \pm 1.2$ & $420 \pm 244$ & $44509 \pm 38062$ \\
$\mathrm{P}$ value & $\mathrm{P}=0.08$ & $\mathrm{P}=0.1352$ & $\mathrm{P}=0.7526$ \\
\hline
\end{tabular}

LDH is an enzyme that catalyzes the lactate products by reducing pyruvate in the process of aerobic glycolysis. Nuclear magnetic resonance analyses in metabolic studies have shown that LDH is highly active even in highly oxygenated tissues. ${ }^{(10)}$ Assessment of plasma LDH has an important clinical value to find different pathological conditions or determine their severity. The main source of salivary LDH is the oral mucosal epithelium. Epithelial cells release LDH into the saliva. Thus, changes in the salivary level of LDH are likely due to pathological changes of the oral epithelium, and saliva may be used for monitor- 
ing of the LDH level similar to plasma. Cigarette smoke can degrade the LDH isoenzymes, and significantly decrease the activity of LDH.

The salivary level of amylase is an indirect marker of the sympathetic adrenomedullary system, and the salivary level of alpha amylase is measured as a marker for the activity of the sympathetic nervous system. ${ }^{(3)}$

LDH and amylase are two important salivary enzymes that decrease in the process of oxidative stress. In the present study, the levels of LDH and amylase in the case group were lower than the corresponding values in the control group, but not significantly. The present results regarding amylase were in line with those of Nater et al, ${ }^{(23)}$ Duskova et al, ${ }^{(3)}$ and Ahmady Motamayel et $\mathrm{al},{ }^{(24)}$ who showed that smoking had no significant effect on the salivary level of amylase. Nagler et al, ${ }^{(10,25,26)}$ and Greabu et al. ${ }^{(19)}$ reported a significant reduction in level of LDH and amylase due to smoking, and showed that cigarette smoke decreased the concentration of important salivary enzymes. Also, Weiner et al. ${ }^{(27)}$ indicated a significant reduction in salivary amylase and Avezov et al. ${ }^{(28)}$ demonstrated a significant reduction in the activity of LDH due to exposure to cigarette smoke. Zappacost et al. ${ }^{(29)}$ demonstrated that cigarette smoking significantly decreased the level of amylase and LDH. However, the level of these enzymes increased again after $60 \mathrm{~min}$. Some of the abovementioned studies had an in vitro design and reported the results following exposure to cigarette smoke. However, in the present study, the patients refrained from smoking for $1 \mathrm{~h}$ prior to saliva collection, and by secretion of new saliva into the oral cavity, the concentration of UA, LDH, and amylase probably increased again. Also, periodontal status affects the salivary antioxidant system, which was standardized in the two groups in the present study. This was a strength of this study, and has not been performed in any previous study.

The salivary antioxidant system has gained the spotlight in the recent years. ${ }^{(11)}$ Antioxidants maintain the oral health by fighting free radicals. ${ }^{(8)}$ Cigarette smoke has over 4000 chemical agents; out of which, 400 are carcinogenic. $^{(30)}$ Also, cigarette smoke has free radicals, which cause tissue damage by reacting with poly-unsaturated fatty acids in the cell membrane and nucleotides in the DNA structure. ${ }^{(8)}$ Such adverse events in the oral environment and in presence of cigarette smoke can play an important role in development and progression of malignant and premalignant oral lesions. ${ }^{(10)}$

Cigarette smoke contains hydrogen cyanide, which is metabolized by the liver into the saliva thiocyanate, which is broken down in the plasma and is secreted into the oral cavity by the parotid gland. ${ }^{(7)}$ The level of saliva thiocyanate can be measured to estimate oxidative stress. ${ }^{(1)}$ The salivary antioxidant system is an important host immunity mechanism and particularly attacks the free radicals of cigarette smoke and prevents oral cancer. ${ }^{(11)}$ The anti-carcinogenic activity of the saliva against oral cancer is such that saliva can inhibit mutations due to known risk factors for oral cancer such as cigarette smoke, $4 \mathrm{NQO}$, and benzopyrene. ${ }^{(11)}$ A preliminary study showed that cigarette smoke may impair the protective effect of salivary antioxidants. ${ }^{(30)}$ In the present study, lack of a significant difference in the measured parameters between smokers and non-smokers may be due to the compensatory activity of the human body to confront harmful agents. Poor cooperation of some patients was a limitation of this study.

\section{Conclusion}

This study did not show any significant difference in the salivary levels of UA, LDH, or amylase between smokers and non-smokers. Future studies are required to measure the salivary levels of these enzymes immediately after smoking and for some time after it.

\section{References}

1-Kanehira T, Shibata K, Kashiwazaki H, Inoue N, Morita $M$. Comparison of antioxidant enzymes in saliva of elderly smokers and non-smokers. Gerodontology. 2006 Mar;23(1):38-42.

2- aharvand M, Maghami AG, Azimi S, Bastani H, Ahmadieh A, Taghibakhsh M. Comparison of superoxide dismutase activity in saliva of smokers and nonsmokers. South Med J. 2010 May;103(5):425-7.

3- Rodrigues L, Mouta R, Costa AR, Pereira A, Capela e Silva F, Amado F, Antunes CM, Lamy E. Effects of high-fat diet on salivary $\alpha$-amylase, serum parameters and food consumption in rats. Arch Oral Biol. 2015 Jun;60(6):854-62. 
4- Shankar H, Selvam TTP. A comparative study of antioxidants in smokers and nonsmokers. APJR 2016; 1(36):152-7. 5- Diaz LB,Tonzar TT, Santos DR, Souza RO, Ribas TB, Silva LF, et al. Salivary biomarkers of cellular damage and oxidative stress following of lower third molar surgical removal. Arch Health Invest 2020; 9(1):11-7.

6- Buduneli N, Kardeşler L, Işik H, Willis CS 3rd, Hawkins SI, Kinane DF, Scott DA. Effects of smoking and gingival inflammation on salivary antioxidant capacity. J Clin Periodontol. 2006 Mar;33(3):159-64.

7- Didilescu AC, Hanganu SC, Galie N, Greabu M, Totan A, Stratul SI, Puiu L. Rolul fumatului in modificarea unor parametri esenţiali in homeostazia organismului [The role of smoking in changing essential parameters in body homeostasis]. Pneumologia. 2009 Apr-Jun;58(2):89-94.8- 8-Zappacosta B, Persichilli S, De Sole P, Mordente A, Giardina B. Effect of smoking one cigarette on antioxidant metabolites in the saliva of healthy smokers. Arch Oral Biol. 1999 Jun;44(6):485-8.

9- Nagler R, Lischinsky S, Diamond E, Drigues N, Klein I, Reznick AZ. Effect of cigarette smoke on salivary proteins and enzyme activities. Arch Biochem Biophys. $2000 \mathrm{Jul}$ 15;379(2):229-36.

10- Nagler RM, Lischinsky S, Diamond E, Klein I, Reznick AZ. New insights into salivary lactate dehydrogenase of human subjects. J Lab Clin Med. 2001 May;137(5):363-9.

11- Reznick AZ, Klein I, Eiserich JP, Cross CE, Nagler RM. Inhibition of oral peroxidase activity by cigarette smoke: in vivo and in vitro studies. Free Radic Biol Med. 2003 Feb 1;34(3):377-84

12- Bakhtiari S, Bigom Taheri J, Bakhshi M, Mortazavi H, Shah Hoseini A, Vahid Dastjerdi E, Azimi S. Effect of vitamin $\mathrm{C}$ on salivary total antioxidant capacity in smokers. Iran J Pharm Res. 2012 Fall;11(4):1045-9.

13- Abdolsamadi HR, Goodarzi MT, Mortazavi H, Robati M, Ahmadi-Motemaye F. Comparison of salivary antioxidants in healthy smoking and non-smoking men. Chang Gung Med J. 2011 Nov-Dec;34(6):607-11.

14- Fatima G, Uppin RB, Kasagani S, Tapshetty R,Rao A. Comparison of salivary uric acid level among individuals without periodontitis with that of smokers and nonsmokers with periodontitis. Journal of advanced oral research 2016;7(1): 24-8.

15- Javaraiah RK, David CM, Namitha J, Tiwari R, Benakanal P. Evaluation of Salivary Lactate Dehydrogenase as a Prognostic Biomarker in Tobacco Users with and without Potentially Malignant Disorders of the Oral Cavity. South Asian J Cancer. 2020 Jun;9(2):93-8.

16- Singh U, SolankiV, Mehrotra S, Sharma R. An Evaluation of Applicability of Salivary Uric Acid Measurement in Preeclampsia and Normal Pregnancy and Its Correlation with Serum Uric Acid. J Obstet Gynaecol India. 2019; 69(1): 62-8.

17- Cochran B, Lunday D, Miskevich F. Kinetic Analysis of Amylase Using Quantitative Benedict's and Iodine Starch Reagents. Journal of Chemical Education 2008;85( 3):401-3 18- Pullishery F, Panchmal GS, Siddique S. Salivary thiocyanate, uric acid and $\mathrm{PH}$ as biomarkers of periodontal disease in tobacco users and non users- an in vitro study. J Clin Diag Res 2015; 9(7): ZC47- ZC50

19- Greabu M, Battino M, Totan A, Mohora M, Mitrea N,
Totan C, Spinu T, Didilescu A. Effect of gas phase and particulate phase of cigarette smoke on salivary antioxidants. What can be the role of vitamin $\mathrm{C}$ and pyridoxine? Pharmacol Rep. 2007 Sep-Oct;59(5):613-8.

20- Hanna BE, Hamed JM, Touhala LM. Serum uric Acid in smokers. Oman Med J. 2008 Oct;23(4):269-74.

21- Babaei M, Shamsi R, Heidari B, Bijani A, Hosseini SR. Serum Uric Acid Status and Its Association with Bone Mineral Density in the Elderly People Aged 60 Years and More. Int J Endocrinol Metab. 2019 Jul 9;17(3):e80780.

22- Vernerová A, Kujovská Krčmová L, Melichar B, Švec F. Non-invasive determination of uric acid in human saliva in the diagnosis of serious disorders. Clin Chem Lab Med. 2020 Nov 30;59(5):797-812.

23- Nater UM, Rohleder N, Schlotz W, Ehlert U, Kirschbaum C. Determinants of the diurnal course of salivary alphaamylase. Psychoneuroendocrinology. 2007 May;32(4):392401.

24- Ahmadi-Motamayel F, Falsafi P, Goodarzi MT, Poorolajal J. Evaluation of salivary catalase, vitamin C, and alphaamylase in smokers and non-smokers: a retrospective cohort study. J Oral Pathol Med. 2017 May;46(5):377-380.

25- Nagler RM. Altered salivary profile in heavy smokers and its possible connection to oral cancer. Int J Biol Markers. 2007 Oct-Dec;22(4):274-80.

26- Nagler RM, Klein I, Reznick AZ. [The interaction between saliva and cigarette smoke and its devastating biological effects as related to oral cancer]. Harefuah. 2001 Jul;140(7):614-8.

27- Weiner D, Levy Y, Khankin EV, Reznick AZ. Inhibition of salivary amylase activity by cigarette smoke aldehydes. J Physiol Pharmacol. 2008 Dec;59 Suppl 6:727-37.

28- Avezov K, Reznick AZ, Aizenbud D. LDH enzyme activity in human saliva: the effect of exposure to cigarette smoke and its different components. Arch Oral Biol. 2014 Feb;59(2):142-8.

29- Zappacosta B, Persichilli S, Mordente A, Minucci A, Lazzaro D, Meucci E, Giardina B. Inhibition of salivary enzymes by cigarette smoke and the protective role of glutathione. Hum Exp Toxicol. 2002 Jan;21(1):7-11.

30- Nagler R, Lischinsky S, Diamond E, Drigues N, Klein I, Reznick AZ. Effect of cigarette smoke on salivary proteins and enzyme activities. Arch Biochem Biophys. 2000 Jul 15;379(2):229-36.

\section{Cite this paper as}

Simin Lesan, Mandana Khatibi, Sina Firoozan. Salivary levels of uric acid, lactate dehydrogenase, and amylase in smokers versus non-smokers. J Res Dent Maxillofac Sci.2021;6(3):18-22. 